\title{
Nisbah Jenis Kelamin Hasil Penetasan Telur Itik Cihateup dan Alabio
}

\author{
Sex Ratio Duck Egg Hatching Results Cihateup and Alabio \\ M. Kholid ${ }^{1)}$, Rukmiasih'), R. Afnan'1) \\ 1) Departemen Ilmu Produksi dan Teknologi Peternakan, Fakultas Peternakan, Institut Pertanian Bogor \\ Jln. Agatis, Kampus IPB Darmaga, Bogor16680
}

\begin{abstract}
Duck eggs are more difficult to hatch than chicken eggs as the duck does not incubate their eggs and the duck eggs need more time to hatch (in 28 days). This study aimed to determine the sex ratio of DOD (Day Old Duck) from two different breeds, namely cihateup from Tasikmalaya West Java and alabio from South Kalimantan. This experiment was conducted from May 2012 to July 2012 at the Hatchery Laboratory of Animal Science Faculty of IPB. 500 eggs consist of 300 alabio eggs and 200 cihateup eggs were used in this experiment. Temperature, humidity, egg weight, egg shape index, hatching weight and mortality were measured. The data of egg weight, egg shape index, and hatching weight were analyzed using t-test, the data of sex ratio DOD were analyzed using chi-square test. The result showed that there were no significant difference between egg weight and egg shape index on sex ratio. Sex ratio of male and female cihateup ducks was equal $(50 \%: 50 \%)$, however the sex ratio of alabio ducks was different (32\%:68\%). Mortality rate was affected by sex of duck $(\mathrm{P}<0.05)$. The Higher mortality was occured at early (day $0-7$ ) and late (day $>25)$ hatching period.
\end{abstract}

Keywords: Anas plathyrynchos borne, Anas plathyrynchos javanic, Sex ratio

\section{PENDAHULUAN}

Itik lokal yang ada di Indonesia pada umumnya dikenal sebagai penghasil telur. Jenis itik lokal yang sudah dikenal masyarakat diantaranya itik cihateup yang berasal dari Tasikmalaya Jawa Barat dan itik alabio yang berasal dari Kalimantan Selatan. Itik tersebut sebagai penghasil telur yang baik. Kedua jenis itik tersebut sering dimanfaatkan sebagai penghasil daging karena keduanya memiliki badan yang relatif besar. Permintaan terhadap daging itik meningkat dalam beberapa tahun terakhir ini. Itik jantan dapat dimanfaatkan sebagai itik potong untuk memenuhi permintaan tersebut karena untuk perkembangbiakannya, itik jantan hanya diperlukan sekitar 10\%-20\%. Sementara itu, itik betina dapat dipelihara lebih lanjut sebagai penghasil telur.

Nisbah jenis kelamin jantan dan betina dari hasil perkawinan akan menghasilkan peluang satu berbanding satu, namun pengaruh dari gen letal dan perubahan kondisi asam-basa dalam saluran kelamin betina dapat menghasilkan nisbah kelamin yang berbeda setelah penetasan (Sukra et al. 1989). Warwick et al. (1998) menyatakan bahwa jenis kelamin sangat ditentukan oleh susunan kromosom dari tetuanya. Kromosom jenis kelamin jantan pada bangsa burung ditandai kode ZZ (homogametik), sedangkan jenis kelamin betina kromosom kelaminnya diidentifikasi dengan kode ZW (heterogametik). Itik jantan yang menetas dibutuhkan lebih banyak untuk penghasil daging, sedangkan itik betina yang menetas lebih banyak dibutuhkan untuk penghasil telur konsumsi dan telur tetas.
Berdasarkan hal tersebut, maka dilakukan penelitian untuk mengetahui nisbah jenis kelamin yang diproleh dari penetasan itik cihateup dan itik alabio, untuk pengembangan usaha peternakan itik yang disesuaikan tujuan produksinya.

\section{MATERI DAN METODE}

Penelitian bertempat di Laboratorium Unit Penetasan Telur Unggas Fakultas Peternakan Institut Pertanian Bogor.

Materi yang digunakan dalam penelitian ini adalah telur tetas itik sebanyak 500 butir, terdiri dari 200 butir telur itik cihateup dan 300 butir telur itik alabio. Telur tetas itik cihateup diperoleh dari daerah Tasikmalaya. Pemeliharaan dilakukan secara semi intensif dengan rasio induk 1:10 (jantan:betina) dan umur induk 7-8 bulan. Telur itik alabio diperoleh dari daerah Kalimantan Selatan yang dipelihara secara intensif, dengan rasio induk 1:10 (jantan:betina) dan umur induk 6 bulan. Bahan sanitasi yang digunakan adalah deterjen, karbol, kalium peramanganat $\left(\mathrm{KMnO}_{4}\right)$, formalin $40 \%$ dan air.

Peralatan yang digunakan dalam penelitian ini adalah jangka sorong, timbangan, seperangkat mesin tetas telur itik otomatis dan seperangkat hatcher. Peralatan lain adalah termometer bola kering dan bola basah, candler telur, gelas ukur, pinset, cawan petri dan gunting bedah, alat semprot (sprayer), pita ukur, amplas halus, nampan dan wadah tahan panas untuk fumigasi.

Metode penelitian ini diawali dengan persiapan 
bahan dan alat. Perangkat mesin tetas seperti rak setter, rak hatcher, nampan, semprotan (sprayer) dibersihkan menggunakan deterjen. Tahap selanjutnya yaitu melakukan fumigasi mesin dan peralatan selama 30 menit dengan dosis tiga kekuatan. Fumigan yang digunakan adalah $\mathrm{KMnO}_{4}$ sebanyak 9,9 g dan Formalin 40\% sebanyak 19,8 ml untuk volume mesin $0,165 \mathrm{~m}^{3}$. Pengaturan suhu mesin tetas (setting mesin tetas) dilakukan sampai suhu dan kelembaban stabil dan sesuai kebutuhan yaitu $37,3{ }^{\circ} \mathrm{C}$ dan kelembaban $70 \%-80 \%$.

Telur tetas yang diperoleh dikelompokkan antara telur bersih dan kotor. Telur tetas yang kotor dibersihkan perlahan menggunakan amplas nomor 0 (nol). Peneropongan telur (candling telur) dilakukan untuk mengetahui keutuhan telur, besar kecilnya kantung udara dan kualitas dalam telur. Telur diberi nomor, ditimbang, diukur panjang dan lebar telur serta difumigasi. Telur tetas difumigasi dengan dosis dua kekuatan selama 15 menit dengan fumigan $\mathrm{KMnO}_{4}$ sebanyak 3,2 g dan formalin 40\% sebanyak 6,4 ml sesuai dengan ruang fumigasi yaitu $0,16 \mathrm{~m}^{3}$.

Telur yang telah difumigasi langsung dimasukkan ke dalam mesin setter (pengeraman) selama 25 hari, selanjutnya telur diletakkan di hatcher (penetasan) selama 3 hari (sampai menetas). Peneropongan telur dilakukan pada hari ke-7 pengeraman untuk mengetahui fertilitasnya. Telur fertil dimasukkan kembali ke mesin setter. Peneropongan ke-2 (umur 25 hari) untuk mengetahui kondisi telur fertil hidup, fertil mati atau busuk, yaitu saat transfer telur fertil hidup dari rak setter ke hatcher (penetasan).

Pemutaran telur dimulai pada hari ke-3 sampai hari ke-25 sebanyak tiga kali dalam satu hari yaitu pada pagi jam 06.00-07.00 WIB, siang jam 12.00-13.00 WIB dan sore jam 18.00-19.00 WIB. Hari ke-26 sampai hari ke-28 tidak dilakukan pemutaran. Pendinginan telur dimulai pada hari ke-3 sampai hari ke-25 dua kali dalam satu hari, yaitu pada pagi jam 06.00-07.00 WIB dan sore jam 18.00-19.00 WIB. Frekuensi pendinginan telur pada proses hatcher (penetasan) menjadi tiga kali dalam satu hari yaitu pada pagi jam 06.0007.00 WIB, siang jam 12.00-13.00 WIB dan sore jam 18.0019.00 WIB. Pencatatan suhu dan kelembaban pada mesin tetas dilakukan pada pagi jam 06.00-07.00 WIB, siang jam 12.00-13.00 WIB dan sore jam 18.00-19.00 WIB.

Jenis kelamin itik yang menetas normal diamati melalui organ kopula di kloaka. Anak itik jantan ditandai dengan tonjolan sebesar ujung jarum, sedangkan pada anak itik betina tidak terdapat tonjolan.

Itik yang tidak berhasil menetas diatas 25 hari dibedah untuk diidentifikasi jenis kelaminnya. Bila terlihat ada dua garis berwarna putih kekuningan pada perbatasan ginjal dan paru-paru, menandakan testis atau jantan. Nisbah kelamin DOD dihitung dari yang menetas normal. Mortalitas embrio dikelompokkan menjadi 3 yaitu umur 0-7 hari, umur 8-25 hari dan umur $>25$ hari.

Peubah yang diamati dalam penelitian ini adalah: Jumlah telur yang ditetaskan, bobot telur dan bentuk telur (indeks), bobot tetas atau bobot DOD (Day Old Duck) dan nisbah jantan, betina yang menetas dan mortalitas embrio.

Analisi Uji t dilakukan pada variabel berat telur, indeks telur dan bobot tetas. Model uji t yang digunakan berdasarkan Steel dan Torrie (1993) adalah sebagai

berikut:

$$
\frac{\mathrm{xi}-\mathrm{xj}-\mathrm{Do}}{\mathrm{s} \sqrt{\frac{1}{\mathrm{n}}}+\sqrt{\frac{1}{\mathrm{n}}}}
$$

Keterangan :

$\mathrm{xi}=$ rata-rata perlakuan ke-i

$\mathrm{xj}=$ rata-rata perlakuan ke-j

$\mathrm{S}$ = simpangan baku

$\mathrm{n} \quad=$ jumlah individu sampel

Do $=$ selisih 2 rataan yang berbeda

Data nisbah kelamin DOD (Day Old Duck) jantan dan betina menggunakan chi-square test (uji chi-kuadrat). Model chi-square test yang digunakan berdasarkan Noor (2010) adalah sebagai berikut:

$$
\mathrm{X}^{2}=\sum \frac{(\mathrm{O}-\mathrm{E})^{2}}{\mathrm{E}}
$$

Keterangan

$\mathrm{X}^{2}=$ chi-kuadrat

$\mathrm{O}=$ nilai pengamatan

$\mathrm{E}=$ nilai harapan

$\Sigma=$ sigma (jumlah dari nilai-nilai)

Data yang diamati dalam penelitian ini adalah suhu dan kelembaban, indeks telur, bobot telur, bobot DOD, nisbah kelamin DOD jantan dan betina dan mortalitas. Suhu dan kelembaban diperoleh dengan cara mencatat suhu dan kelembaban dalam mesin tetas sebanyak 3 kali dalam sehari. Indeks bentuk telur diukur sebelum telur dimasukkan ke dalam mesin penetas. Indeks telur diperoleh dari:

$$
\text { Indeks telur }=\frac{\text { Lebar telur }}{\text { Panjang telur }} \times 100 \%
$$

Bobot telur tetas diukur sebelum telur dimasukkan ke dalam mesin tetas setter. Bobot tetas atau bobot DOD didapatkan dari penimbangan DOD saat menetas.

Nisbah jantan dan betina setelah dilakukan sexing diperoleh dari:

$$
\text { Nisbah kelamin }=\frac{\sum \text { DOD Jantan }}{\sum \text { DOD }} \times 100 \%
$$

Mortalitas embrio menunjukkan persentase jumlah embrio yang tidak menetas, diperoleh dari:

$$
\text { Mortalitas }=\frac{\text { Jumlah telur yang mati }}{\text { Jumlah telur diinkubasi }} \times 100 \%
$$

\section{HASIL DAN PEMBAHASAN}

\section{Suhu dan Kelembaban Mesin Tetas}

Rataan suhu dan kelembaban dalam mesin tetas selama proses penetasan dapat dilihat pada Tabel 1.Kondisi suhu dan kelembaban mesin tetas selama proses penetasan setter dan hatcher berdasarkan umur penetasan dicatat pada waktu pagi, siang dan sore. Suhu penetasan selama proses setter dalam penelitian ini pada umur penetasan 0-7 hari rata-rata berkisar $37,9 \pm 0,16{ }^{\circ} \mathrm{C}$, umur penetasan $8-25$ hari 
Tabel 1 Suhu dan kelembaban selama proses penetasan setter dan hatcher berdasarkan umur penetasan

\begin{tabular}{|c|c|c|c|c|}
\hline \multirow[t]{3}{*}{ Waktu proses penetasan } & \multirow{3}{*}{$\begin{array}{c}\mathrm{T} \\
\mathrm{RH}\end{array}$} & \multicolumn{3}{|c|}{ Periode } \\
\hline & & \multicolumn{2}{|c|}{ Setter } & Hatcher \\
\hline & & $0-7$ hari & $8-25$ hari & $>25$ hari \\
\hline \multirow[t]{2}{*}{ Pagi (06.00-07.00) } & ${ }^{\circ} \mathrm{C}$ & $37,7 \pm 0,5$ & $38 \pm 0,0$ & $37,3 \pm 0,20$ \\
\hline & $\%$ & $66,9 \pm 5,53$ & $71,2 \pm 3,86$ & $75,5 \pm 3,77$ \\
\hline \multirow[t]{2}{*}{ Siang (12.00-13.00) } & ${ }^{\circ} \mathrm{C}$ & $38 \pm 0,0$ & $36,4 \pm 2,60$ & $37,5 \pm 0,14$ \\
\hline & $\%$ & $69,9 \pm 8,10$ & $75,3 \pm 6,20$ & $76 \pm 4,33$ \\
\hline \multirow[t]{2}{*}{ Sore (18.00-19.00) } & ${ }^{\circ} \mathrm{C}$ & $38 \pm 0,0$ & $38 \pm 0,0$ & $37,3 \pm 0,15$ \\
\hline & $\%$ & $67,8 \pm 9,02$ & $71,8 \pm 3,57$ & $76,7 \pm 3,01$ \\
\hline \multirow[t]{2}{*}{ Rata-rata \pm sd } & ${ }^{\circ} \mathrm{C}$ & $37,9 \pm 0,16$ & $37,4 \pm 0,86$ & $37,4 \pm 0,16$ \\
\hline & $\%$ & $68,2 \pm 7,55$ & $72,8 \pm 4,55$ & $76,1 \pm 3,70$ \\
\hline
\end{tabular}

Keterangan : $\mathrm{T}=$ suhu; $\mathrm{RH}=$ kelembaban

Tabel 2 Bobot telur, indeks dan bobot tetas itik alabio dan itik cihateup

\begin{tabular}{lcccccc}
\hline Telur Itik & \multicolumn{2}{c}{ Bobot Telur $(\mathrm{g})$} & \multicolumn{2}{c}{ Indeks Telur $(\%)$} & \multicolumn{2}{c}{ Bobot Tetas $(\mathrm{g})$} \\
\cline { 2 - 6 } & Jantan & Betina & Jantan & Betina & Jantan & Betina \\
\hline Cihateup & $71,61 \pm 3,62 \mathrm{~b}$ & $72,29 \pm 4,16 \mathrm{~b}$ & $80,06 \pm 2,03 \mathrm{~b}$ & $80,28 \pm 4,30 \mathrm{~b}$ & $42,69 \pm 3,72 \mathrm{~b}$ & $42,25 \pm 4,11 \mathrm{~b}$ \\
Alabio & $66,37 \pm 4,77 \mathrm{a}$ & $67,12 \pm 3,50 \mathrm{a}$ & $78,32 \pm 3,74 \mathrm{a}$ & $77,89 \pm 3,14 \mathrm{a}$ & $39,21 \pm 4,20 \mathrm{a}$ & $39,13 \pm 3,33 \mathrm{a}$ \\
\hline
\end{tabular}

Keterangan: a,b yang berbeda pada kolom dan peubah yang sama menunjukkan perbedaan nyata $(\mathrm{P}<0,05)$

rata-rata berkisar $37,4 \pm 0,86{ }^{\circ} \mathrm{C}$ dan umur penetasan $>25$ hari rata-rata berkisar $37,4 \pm 0,16{ }^{\circ} \mathrm{C}$. Suhu rata-rata dalam proses penetasan $0,1^{\circ} \mathrm{C}$ sampai $0,6{ }^{\circ} \mathrm{C}$ lebih tinggi dari yang disarankan. Suhu ideal yang disarankan untuk periode inkubasi (setter) pada itik adalah $37,3^{\circ} \mathrm{C}$ dan selama periode penetasan (hatcher) $36,9^{\circ} \mathrm{C}$. Suhu yang terlalu tinggi atau terlalu rendah dari yang disarankan akan memiliki efek buruk pada daya tetas atau menimbulkan kematian. Efek lainnya dari suhu lebih tinggi adalah akan menetas lebih awal, sedangkan pada suhu lebih rendah akan menetas lebih lambat. Bila di dalam penetasan telur itik terjadi kenaikan suhu $0,5^{\circ} \mathrm{C}$ selama 3 hari maka akan menurunkan daya tetas sampai 50\% dari yang diharapkan (Kortlang 1985).

Keberhasilan perkembangan embrio sangat dipengaruhi oleh temperatur dan kelembaban mesin tetas, lama penyimpanan telur, kualitas kerabang dan pori-pori telur, nutrisi, dan genetik (Ngobe 2003). Rataan kelembaban pada umur penetasan 8-25 hari cukup ideal yaitu 72,8 $\pm 4,55$

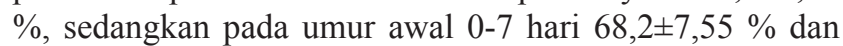
umur $>25$ hari $76,1 \pm 3,70 \%$ lebih rendah dari yang disarankan kortlang (1985). Standar relatif kelembaban selama masa inkubasi (1-25 hari) 70\%-79\% harus dipertahankan selama 26 hari. Kelembaban harus meningkat menjadi 90\%-94\% setelah 26 hari (Kortlang 1985). Kelembaban yang terlalu tinggi akan mencegah terjadinya penguapan air dari dalam telur disamping itu kelembaban yang terlalu rendah dapat menyebabkan terjadinya penguapan air yang terlalu banyak dari dalam telur sehingga akan terjadi kematian embrio.

\section{Bobot Telur, Indeks Telur dan Bobot Tetas}

Rataan bobot telur, indeks telur dan bobot tetas dari hasil pengukuran semua telur yang ditetaskan disajikan pada Tabel 2.

Klasifikasi bobot dalam industri penetasan telur sangat penting dilakukan karena berkaitan dengan bobot tetas yang diinginkan dan harga jual dari telur tersebut. Indikator bobot tetas dapat dilihat dari bobot telur awal. Bobot telur yang lebih tinggi akan menghasilkan bobot tetas yang lebih besar begitu juga sebaliknya. Kortlang (1985) menyatakan bobot telur itik yang baik untuk ditetaskan antara 65-75 g dengan bentuk yang normal. Bobot telur pada penelitian ini tidak berbeda nyata antara bobot telur itik yang menetas jantan dan betina artinya bobot telur tidak mempengaruhi jenis kelamin itik yang menetas. Hal ini terjadi baik pada telur yang berasal dari itik alabio maupun telur yang berasal dari itik cihateup. Burke (1992) menyatakan tidak ada hubungan jenis kelamin dengan bobot telur yang digunakan.

Bobot telur mempengaruhi bobot tetas dapat dilihat pada Tabel 2. Bobot telur yang besar (telur itik cihateup) menghasilkan anak itik (DOD) dengan bobot tetas yang besar, sebaliknya bobot telur yang kecil (telur itik alabio) menghasilkan anak itik dengan bobot tetas yang kecil. Hal ini berlaku untuk jenis kelamin jantan maupun betina. Lasmini dan Heriyati (1992) menyatakan bahwa bobot telur itik yang lebih besar menghasilkan bobot tetas $D O D$ lebih tinggi daripada telur tetas yang kecil. Hal ini berhubungan dengan sumber makanan bagi embrio lebih banyak pada telur large daripada medium dan small, sehingga menghasilkan bobot DOD kelompok large lebih besar dari medium dan small.

Indeks telur merupakan bentuk telur yang terlihat lebih panjang atau lebih bulat. Dharma et al. (2001) menjelaskan indeks telur mencerminkan bentuk telur sangat dipengaruhi sifat genetik, bangsa serta proses pembentukan telur, terutama pada saat telur melalui magnum dan isthmus. Dharma et al. (2001) menyatakan nilai yang lebih kecil dari 79\% akan memberikan penampilan lebih panjang, sedangkan nilai yang lebih besar dari 79\% akan memberikan 
Tabel 3 Nisbah jenis kelamin DOD yang hidup dari itik cihateup dan itik alabio

\begin{tabular}{|c|c|c|c|c|c|c|c|c|}
\hline \multirow[t]{3}{*}{ Telur } & \multirow[t]{2}{*}{ Jumlah telur } & \multirow{2}{*}{$\begin{array}{c}\text { Jumlah Telur Masuk } \\
\text { Hatcher }\end{array}$} & \multicolumn{4}{|c|}{ Nisbah Kelamin DOD Hidup } & \multicolumn{2}{|c|}{$\mathrm{X}^{2}$} \\
\hline & & & $\hat{\sigma}$ & $q$ & \multirow[t]{2}{*}{$\hat{0}$} & \multirow[t]{2}{*}{ q } & \multirow[t]{2}{*}{ hitung } & \multirow[t]{2}{*}{ tabel } \\
\hline & & ...(butir).... & & & & & & \\
\hline Cihateup & 200 & 90 (32 ekor hidup) & 50 & 50 & 16 ekor (16)E & 16 ekor (16)E & 0 tn & 3,84 \\
\hline Alabio & 300 & 259 (150 ekor hidup) & 32 & 68 & 48 ekor $(75) \mathrm{E}$ & 102 ekor $(75) \mathrm{E}$ & $19,44 * *$ & 6,64 \\
\hline
\end{tabular}

Keterangan $: \operatorname{tn}=$ tidak nyata; $* *=$ sangat nyata; $\mathrm{E}=$ harapan; $\hat{\sigma}=$ jantan; $\phi=$ betina

Tabel 4 Hubungan jenis kelamin dengan mortalitas DOD itik cihateup dan itik alabio

\begin{tabular}{|c|c|c|c|c|c|c|c|}
\hline \multirow[t]{2}{*}{ Telur } & \multirow{2}{*}{$\begin{array}{l}\text { Jumlah } \\
\text { Telur }\end{array}$} & \multirow{2}{*}{$\begin{array}{c}\text { Jumlah Telur Masuk } \\
\text { Hatcher }\end{array}$} & \multicolumn{3}{|c|}{ Nisbah Kelamin DOD Mati } & \multicolumn{2}{|c|}{$\mathrm{X}^{2}$} \\
\hline & & & 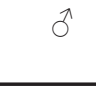 & $q$ & Tidak Teridentifikasi & $\begin{array}{l}\text { hitung (hidup } \\
\text { dan mati) }\end{array}$ & tabel \\
\hline & & \multicolumn{6}{|c|}{ ( } \\
\hline Cihateup & 200 & 90 (58 ekor mati) & 22,41 & 31,04 & 46,55 & $0,41 \mathrm{tn}$ & 3,84 \\
\hline Alabio & 300 & 259 (109 ekor mati) & 34,87 & 40,37 & 24,76 & $4,67 *$ & 3,84 \\
\hline
\end{tabular}

Keterangan $: \mathrm{tn}=$ tidak nyata; $*=$ nyata

penampilan yang lebih bulat. Hal ini dapat dinyatakan bahwa bentuk telur alabio lebih panjang karena indeksnya $<79 \%$ sedangkan telur cihateup lebih bulat karena indeksnya $>79 \%$. Hal ini dipengaruh oleh genetik dan bangsa.

Indeks telur yang dihasilkan pada penelitian ini tidak mempengaruhi jenis kelamin itik yang menetas (Tabel 2). Hal ini terjadi baik pada telur yang berasal dari itik alabio maupun telur yang berasal dari itik cihateup. Hal ini menunjukkan bahwa indeks telur tidak dapat dijadikan untuk mengidentifikasi bahwa telur tersebut akan menghasilkan itik jantan atau betina. Hal ini sesuai dengan pernyataan North dan Bell (1990) bahwa bentuk telur, posisi kantong udara atau faktor lain tidak ada hubungannya dengan jenis kelamin.

\section{Nisbah Jenis Kelamin DOD (Day Old Duck)}

Persentase nisbah jenis kelamin DOD yang hidup dari itik cihateup dan itik alabio yang menetas ditampilkan pada Tabel 3.

Nisbah jenis kelamin jantan betina DOD yang hidup pada itik cihateup adalah 50\%:50\%, sedangkan pada itik alabio yaitu 32\%:68\%. Hal ini menunjukkan bahwa nisbah jenis kelamin DOD antara itik cihateup dan itik alabio tidak sama (berbeda). Itik alabio tidak sesuai dengan Noor (2010) yang menyatakan bahwa peluang munculnya jenis kelamin jantan betina adalah 50:50.

Nisbah jenis kelamin DOD yang hidup dengan menggunakan chi-square test (uji chi-kuadrat) dapat dilihat pada Tabel 3. Nisbah DOD itik cihateup dapat dinyatakan tidak nyata $\left(\mathrm{X}^{2}\right.$ hitung $<\mathrm{X}^{2}$ tabel), artinya nisbah jenis kelamin DOD itik cihateup tidak menyimpang dari rasio harapan 1:1. Nisbah DOD itik alabio dapat dinyatakan sangat nyata $\left(\mathrm{X}^{2}\right.$ hitung $>\mathrm{X}^{2}$ tabel), artinya nisbah jenis kelamin DOD itik alabio menyimpang dari rasio harapan 1:1. Perbedaan tersebut diduga karena perbedaan genetik, sistem pemeliharaan dan pakan induk yang berbeda.

Sistem pemeliharaan induk yang dilakukan pada itik cihateup secara semi intensif dengan pakan komersial, sedangkan pada induk itik alabio dengan sistem pemeliharaan secara intensif dengan pakan komersial dengan tambahan formula bahan pakan yang dibuat sendiri (dedak, sagu, dan tepung ikan).

Manipulasi rasio jenis kelamin berdasarkan kondisi tubuh betina dan kandungan pakan yang diberikan dapat mempengaruhi zat lain yang mempengaruhi kondisi dalam pembentukan jenis kelamin selama miosis (Alonso 2006). Menurut Sukra et al. (1989) perbandingan jenis kelamin dapat dipengaruhi perubahan kondisi asam-basa dalam saluran kelamin betina. Induk betina bisa membatasi motilitas sperma dengan mengubah cairan dalam oviduk, seperti mengubah kalsium, $\mathrm{pH}$ dan viskositas dari cairan tersebut serta perubahan suhu tubuh, hal ini dapat mempengaruhi harapan jenis kelamin (Ashizawa et al. 2000).

\section{Hubungan Jenis Kelamin dengan Mortalitas DOD}

Hubungan antara jenis kelamin dengan mortalitas pada DOD itik cihateup dan itik alabio ditampilkan pada Tabel 4.

Mortalitas DOD itik cihateup berdasarkan jenis kelamin tidak nyata $\left(\mathrm{X}^{2}\right.$ hitung $<\mathrm{X}^{2}$ tabel), artinya hubungan antara jenis kelamin dan mortalitas DOD tidak nyata. Pike dan Petrie (2003) menyatakan tidak ada yang menunjukkan perbedaan mortalitas embrio antar jenis kelamin. Mortalitas DOD itik alabio berhubungan nyata dengan jenis kelamin. Mortalitas DOD itik cihateup dan yang tidak teridentifikasi jenis kelaminnya lebih tinggi dibandingkan dengan DOD itik alabio. Hal ini diduga bahwa perbedaan jenis itik dapat mempengaruhi mortalitas di setiap breed.

Tingkat kematian DOD itik cihateup dan itik alabio jenis kelamin jantan terlihat lebih rendah

dibandingkan dengan tingkat kematian itik betina. Lee et al. (2002) menyatakan bahwa kematian pada betina heterozygot jauh lebih besar dibandingkan dengan jantan homozygot. Hal ini diduga embrio jantan dan betina mempunyai kepekaan (daya tahan) yang berbeda terhadap suhu dan kelembaban penetasan. Brahmantiyo dan Prasetyo (2001) menyatakan bahwa kematian embrio 
yang cukup tinggi diduga karena terjadinya perubahan panas metabolisme embrio yang diakibatkan aktivitas pertumbuhan embrio. Persentase mortalitas embrio dari telur cihateup berdasarkan umur penetasan dari umur 0-7 hari, 8-25 hari dan $>25$ hari disajikan pada Tabel 5 .

Persentase mortalitas embrio telur cihateup tertinggi adalah pada umur $>25$ hari yaitu $42,28 \%$. Hal ini sesuai dengan pendapat North dan Bell (1990) bahwa periode penetasan mengalami masa kritis pada awal masa

Tabel 5 Persentase mortalitas embrio dari telur cihateup berdasarkan umur penetasan

\begin{tabular}{|c|c|c|c|}
\hline $\begin{array}{l}\text { Umur } \\
\text { Telur } \\
\text { (Hari) }\end{array}$ & Mortalitas & Ciri-Ciri Fisik & Penyebab \\
\hline $0-7$ & 23 butir** & \multirow{2}{*}{$\begin{array}{l}\text { Pembuluh } \\
\text { darah sedikit }\end{array}$} & \multirow{2}{*}{$\begin{array}{l}\text { Kekurangan } \\
\text { vitamin* }\end{array}$} \\
\hline Setter & $-15,44 \%$ & & \\
\hline $8-25$ & 31 butir** & \multirow[t]{2}{*}{ Mati/busuk } & \multirow{2}{*}{$\begin{array}{l}\text { Kontaminasi mi- } \\
\text { kro organisme* }\end{array}$} \\
\hline Setter & $-20,8 \%$ & & \\
\hline \multirow[t]{8}{*}{$\begin{array}{l}>25 \\
\text { Hatcher }\end{array}$} & $\begin{array}{l}63 \text { butir** } \\
(42,28 \%)\end{array}$ & $\begin{array}{l}\text { Normal lemah } \\
(6,05 \%)\end{array}$ & Suhu tinggi* \\
\hline & & $\begin{array}{l}\text { Kering } \\
(0,67 \%)\end{array}$ & Dehidrasi* \\
\hline & & $\begin{array}{l}\text { Bulu rontok } \\
(2,68 \%)\end{array}$ & $\begin{array}{l}\text { Kekurangan } \\
\text { nutrisi* }\end{array}$ \\
\hline & & $\begin{array}{l}\text { Kuning telur } \\
\text { diluar }(4,02 \%)\end{array}$ & $\begin{array}{l}\text { Kekurangan } \\
\text { energi* }\end{array}$ \\
\hline & & $\begin{array}{l}\text { Telapak kaki } \\
\text { berhimpitan } \\
(2,02 \%)\end{array}$ & $\begin{array}{l}\text { Kekurangan } \\
\text { nutrisi* }\end{array}$ \\
\hline & & $\begin{array}{l}\text { Kepala kecil } \\
(3,35 \%)\end{array}$ & $\begin{array}{l}\text { Kekurangan } \\
\text { nutrisi* }\end{array}$ \\
\hline & & $\begin{array}{l}\text { Kaki bengkok } \\
(2,02 \%)\end{array}$ & $\begin{array}{l}\text { Kekurangan } \\
\text { nutrisi* }\end{array}$ \\
\hline & & $\begin{array}{l}\text { Busuk/be- } \\
\text { lum piping } \\
(21,47 \%)\end{array}$ & $\begin{array}{l}\text { Kontaminasi } \\
\text { mikroorganisme, } \\
\text { pendarahan otot } \\
\text { dan malposition* }\end{array}$ \\
\hline
\end{tabular}

Sumber : *) North dan Bell (1990);**) Dari telur fertil 149 butir

pengeraman saat terjadi perkembangan sistem peredaran darah, sedangkan pada masa akhir pengeraman saat terjadi perubahan fisioliogis dari sistem pernafasan alantois menjadi gelembung pernafasan (udara).

Umur awal penetasan (1-7 hari) kematian embrio mencapai $15,44 \%$, hal ini diduga akibat kekurangan vitamin yang dapat menghambat laju sistem peredaran darah embrio sehingga pembuluh darah sedikit. Menurut North dan Bell (1990) embrio mati pada umur 3 sampai 6 hari selama inkubasi disebabkan kurangnya ventilasi, karbon dioksida $>1 \%$ dan kurangnya vitamin $\mathrm{A}, \mathrm{D}, \mathrm{E}$, riboflavin, biotin dan asam linoleat. Kematian embrio pada umur 8-25 hari $(20,80 \%)$ berdasarkan cirinya menunjukkan adanya kontaminasi mikro organisme dan kematian embrio umur $>25$ hari, sebagian besar $(21,47 \%)$ karena kontaminasi mikro organisme. Hal ini pengaruh dari mikro organisme menempel pada telur yang kotor sampai di lokasi penetasan sehingga mikro organisme berkembangbiak selama dalam mesin penetasan. Selain itu penyebab berikutnya, yang terdeteksi dari ciri-ciri embrio yang mati adalah karena suhu dan kelembaban (6,72\%) dan kekurangan nutrisi (14,09\%). Suhu yang lebih tinggi dari yang disarankan dengan ciri embrio lemah dan kelembaban rendah ciri embrio kering, sedangkan kekurangan nutrisi berdampak abnormalitas pada embrio seperti bulu rontok, kuning telur diluar, telapak kaki berhimpitan, kepala kecil dan kaki bengkok.

Menurut North dan Bell (1990) embrio mati pada umur 7 sampai 17 hari selama inkubasi disebabkan suhu dan kelembaban tidak tepat, ventilasi kurang dan kelembaban rendah, kekurangan nutrisi (ribovlavin, vitamin $\mathrm{B}_{12}$, biotin miacin) dan gen letal. Embrio mati pada umur $>18$ hari selama inkubasi disebabkan suhu dan kelembaban tidak tepat dan ventilasi kurang serta suhu dan kelembaban pada masa hatcher tidak tepat, kontaminasi terutama pada Aspergillus, fumigasi yang terlalu lama, waktu pendinginan terlambat, kerabang rusak atau retak (kualitas rendah), kekurangan nutrisi (vitamin A, D, E, K asam folik, riboflavin, biotin, vitamin $\mathrm{B}_{12}$, kalsium, fosfor, selenium, asam linoleat dan $\mathrm{Mn}$ ), kesalahan posisi embrio (embrio gagal untuk pindah keposisi menetas yang tepat), genetik (keturunan) dan induk yang sakit.

Persentase mortalitas embrio dari telur alabio berdasarkan umur penetasan dari umur 0-7 hari, 8-25 hari dan $>25$ hari ditampilkan pada Tabel 6 .

Persentase mortalitas embrio telur alabio tertinggi pada umur $>25$ hari yaitu $32,40 \%$ dan pada umur 0-7 hari yaitu 9,07\%. Umur awal penetasan (1-7 hari) kematian embrio diduga akibat kekurangan vitamin yang dapat menghambat laju sistem peredaran darah embrio dan pengaruh transportasi pengiriman yang lebih jauh dibandingkan dengan telur itik cihateup sehingga mempengaruhi kondisi telur dan perkembangan pembuluh darah.

Kematian embrio pada umur 8-25 hari $(6,27 \%)$ berdasarkan cirinya menunjukkan adanya kontaminasi mikro organisme, hal ini pengaruh dari mikro organisme menempel pada telur yang kotor sampai di lokasi penetasan sehingga mikro organisme berkembangbiak selama dalam mesin penetasan. Kematian embrio pada umur akhir penetasan ( $>25$ hari) mencapai $32,40 \%$, sebagian besar $(14,65 \%)$ pengaruh dari suhu dan kelembaban tidak sesuai dari yang disarankan. Selain itu penyebab berikutnya, yang terdeteksi dari ciri-ciri embrio yang mati adalah karena kekurangan nutrisi $(13,92 \%)$ dan kontaminasi mikro organisme $(3,83 \%)$. Kekurangan nutrisi berdampak abnormalitas pada embrio seperti bulu rontok, kuning telur diluar, telapak kaki berhimpitan dan kepala kecil, hal ini diduga pengaruh kurangnya vitamin $\mathrm{B}_{12}$, asam folat, biotin dan $\mathrm{Mn}$.

Tingginya suhu pada umur tersebut dan diiringi metabolisme embrio semakin cepat dapat menguras energi embrio lebih banyak dan cairan lebih cepat menguap, sehingga terjadi dehidrasi, lemah dan tidak dapat memasukkan kuning telur sebagai cadangan makanan embrio bahkan sampai embrio tidak memiliki upaya untuk menerobos kerabang. Cherry dan Morris (2008) 
Tabel 6 Persentase mortalitas embrio dari telur alabio berdasarkan umur penetasan

\begin{tabular}{|c|c|c|c|}
\hline $\begin{array}{l}\text { Umur Telur } \\
\text { (hari) }\end{array}$ & Mortalitas & Ciri-Ciri Fisik & Penyebab \\
\hline \multirow[t]{2}{*}{$\begin{array}{l}0-7 \\
\text { Setter }\end{array}$} & 26 butir** & $\begin{array}{l}\text { Pembuluh } \\
\text { darah sedikit }\end{array}$ & $\begin{array}{l}\text { Kekurangan } \\
\text { vitamin* }\end{array}$ \\
\hline & $-9,07 \%$ & & \\
\hline \multirow[t]{2}{*}{$\begin{array}{l}8-25 \\
\text { Setter }\end{array}$} & 18 butir** & Mati/Busuk & $\begin{array}{l}\text { Kontaminasi } \\
\text { mikroorganisme* }\end{array}$ \\
\hline & $-6,27 \%$ & & \\
\hline \multirow[t]{7}{*}{$\begin{array}{l}>25 \\
\text { Hatcher }\end{array}$} & $\begin{array}{l}\text { 93butir** } \\
(32,40 \%)\end{array}$ & $\begin{array}{l}\text { Normal lemah } \\
(8,37 \%)\end{array}$ & Suhu tinggi* \\
\hline & & Kering $(6,28 \%)$ & Dehidrasi* \\
\hline & & $\begin{array}{l}\text { Bulu rontok } \\
(4,87 \%)\end{array}$ & $\begin{array}{l}\text { Kekurangan } \\
\text { nutrisi* }\end{array}$ \\
\hline & & $\begin{array}{l}\text { Kuning telur } \\
\text { diluar }(3,83 \%)\end{array}$ & $\begin{array}{l}\text { Kekurangan } \\
\text { energi* }\end{array}$ \\
\hline & & $\begin{array}{l}\text { Telapak kaki } \\
\text { berhimpitan } \\
(1,39 \%)\end{array}$ & $\begin{array}{l}\text { Kekurangan } \\
\text { nutrisi* }\end{array}$ \\
\hline & & $\begin{array}{l}\text { Kepala kecil } \\
(3,83 \%)\end{array}$ & $\begin{array}{l}\text { Kekurangan } \\
\text { nutrisi* }\end{array}$ \\
\hline & & $\begin{array}{l}\text { Busuk/belum } \\
\text { piping }(3,83 \%)\end{array}$ & $\begin{array}{l}\text { Kontaminasi } \\
\text { mikroorganisme, } \\
\text { pendarahan otot } \\
\text { dan malposition* }\end{array}$ \\
\hline
\end{tabular}

Sumber : *) North dan Bell (1990);**) Dari telur fertil 287 butir

menyatakan banyak embrio ditemukan mati diantara hari ke-22 sampai hari ke-27 selama inkubasi. Hal ini disebut "dead-in-shell" dan terbagi menjadi tiga kategori. Kategori pertama, embrio tumbuh dan berkembang secara normal, tetapi tidak memiliki upaya untuk menerobos kerabang. Kategori seperti ini biasanya mati pada hari ke-28. Kategori ke-dua mati pada hari yang sama, tetapi menunjukkan karakteristik paruh yang pipih dan lentur dengan oedema serta pendarahan pada otot bagian belakang kepala. Kejadian tersebut merupakan dampak berkelanjutan dari usaha embrio memecah kerabang namun gagal. Kategori ke-tiga mati antara hari ke-22 sampai hari ke-28 disebabkan kesalahan posisi (malposition) selama berkembang, sehingga menghambat embrio tersebut untuk keluar dari kerabang.

\section{KESIMPULAN}

Nisbah jenis kelamin DOD antara itik cihateup 50:50 dan itik alabio 32:68. Bobot telur, indeks telur dan bobot tetas tidak mempengaruhi nisbah jenis kelamin DOD. Bobot tetas DOD pada itik alabio dan itik cihateup dipengaruhi oleh bobot telur. Mortalitas tertinggi terjadi pada umur awal penetasan 0-7 hari (cihateup, alabio) dan umur akhir penetasan $>25$ hari (alabio). Jenis kelamin mempengaruhi mortalitas DOD itik alabio, mortalitas DOD itik alabio betina $(40,37 \%)$ lebih tinggi dibandingkan itik alabio jantan $(34,87 \%)$.

\section{DAFTAR PUSTAKA}

Alonso AC. 2006. Manipulation of primary sex-ratio: an updated review. Avian Poult. Biol. Rev. (17):1-20.

Ashizawa K, Wishart, GJ, Tsuzuki Y. 2000 Avian sperm motility: environmental and intracellular regulation. Avian Poult. Biol. Rev. (11):161 - 172.

Brahmantiyo B, Prasetyo LH. 2001. Pengaruh bangsa itik Alabio dan Mojosari terhadap performans reproduksi. Di dalam : Perkembangan teknologi Peternakan unggas air di Indonesia [Prosiding] Lokakarya Unggas Air I Pengembangan Agribisnis unggas air sebagai peluang usaha baru. Bogor (ID). Balai Penelitian Ternak, Pusat Penelitian dan Pengembangan Peternakan, Departemen Pertanian dan Fakultas Peternakan IPB.

Burke WH. 1992. Sex difference in incubation length and hatching weight of broiler chicks. Department of Poultry Science, The University of Georgia, Athens, Georgia 30602.

Cherry P, Morris TR. 2008. Domestic Duck Production. CABI North American, Massachusett.

Dharma YK, Rukmiasih, Hardjosworo PS. 2001. Ciri-ciri fisik telur tetas itik Mandalung dan rasio jantan dengan betina yang dihasilkan. Lokakarya Unggas Air. Bogor (ID) Balai Penelitian Ternak Ciawi.

Kortlang CFHF. 1985. The Incubation of Duck Egg. In : Duck Production Science and World Practice. University of New England, pp. 168-177.

Lasmini A, Heriyati E. 1992. Pengaruh berat telur terhadap fertilitas, daya tetas dan berat tetas DOD. Pengelolaan dan Komunikasi Hasil-hasil Penelitian Unggas dan Aneka Ternak. Balai Penelitian Ternak Ciawi. Bogor (ID): 35-37.

Lee PL, Brain PF, Forman, DW, Bradbury RB, Griffiths R. 2002. Sex and death: CHD1Z associated with high mortality in moorhens. Evol. Int. J. Org. Evol. (56):2548-2553.

Ngobe M. 2003. Perkembangan bobot dan penampilan embrio itik Alabio dan hasil persilangannya dengan entok jantan sebagai pedoman untuk menduga umur embrio [tesis]. Bogor (ID): Program Pascasarjana, Institut Pertanian Bogor.

Noor RR. 2010. Genetika Ternak. Jakarta (ID): Penebar Swadaya.

North MO, Bell DD. 1990. Commercial Chicken Production Manual. Ed ke-4. An Avia Book Published by Van Nostrand. Reindhold, New York.

Pike TW, Petrie M. 2003. Potential mechanisms of avian sex manipulation. Biol. Rev.(78):553 - 574.

Steel RGD, Torrie JH. 1993. Prinsip dan Prosedur Statistik Suatu Pendekatan Biometrik. Ed ke-3. Sumantri B, penerjemah. Jakarta. (ID): Gramedia Terjemahan dari : Principles and Procedures of Statistics.

Sukra Y, Rahardja L, Djuwita I. 1989. Embriology I. Departemen Pendidikan dan Kebudayaan, Dirjen Pendidikan Tinggi, Pusat Antar Universitas Ilmu Hayati. Bogor (ID). Institut Pertanian Bogor.

Warwick EJ, Maria JA, Harjosubroto W. 1998. Pemuliaan Ternak. Yogyakarta (ID): Gajah Mada University Pr. 